\title{
\begin{tabular}{l|l} 
Mibraries & DSpace@MIT
\end{tabular}
}

\author{
MIT Open Access Articles
}

\section{Development and Characterization of an Air- Cooled Loop Heat Pipe With a Wick in the Condenser}

The MIT Faculty has made this article openly available. Please share how this access benefits you. Your story matters.

Citation: Kariya, H. Arthur; Peters, Teresa B.; Cleary, Martin; Hanks, Daniel F.; Staats, Wayne L.; Brisson, John G. and Wang, Evelyn N.. “Development and Characterization of an Air-Cooled Loop Heat Pipe With a Wick in the Condenser." Journal of Thermal Science and Engineering Applications 6, no. 1 (October 2013): 011010. (c) 2013 American Society of Mechanical Engineers

As Published: http://dx.doi.org/10.1115/1.4025049

Publisher: ASME International

Persistent URL: http://hdl.handle.net/1721.1/108657

Version: Final published version: final published article, as it appeared in a journal, conference proceedings, or other formally published context

Terms of Use: Article is made available in accordance with the publisher's policy and may be subject to US copyright law. Please refer to the publisher's site for terms of use. 


\section{H. Arthur Kariya}

Teresa B. Peters

Martin Cleary

Daniel F. Hanks

Wayne L. Staats ${ }^{1}$

John G. Brisson

Evelyn N. Wang ${ }^{2}$

e-mail: enwang@mit.edu

Department of Mechanical Engineering, Massachusetts Institute of Technology, 77 Massachusetts Avenue, Cambridge, MA 02139

\section{Development and Characterization of an Air-Cooled Loop Heat Pipe With a Wick in the Condenser}

Thermal management of modern electronics is rapidly becoming a critical bottleneck of their computational performance. Air-cooled heat sinks offer ease and flexibility in installation and are currently the most widely used solution for cooling electronics. We report the characterization of a novel loop heat pipe (LHP) with a wick in the condenser, developed for the integration into an air-cooled heat sink. The evaporator and condenser are planar $(102 \mathrm{~mm} \times 102 \mathrm{~mm}$ footprint) and allow for potential integration of multiple, stacked condensers. The condenser wick is used to separate the liquid and vapor phases during condensation by capillary menisci and enables the use of multiple condensers with equal condensation behavior and performance. In this paper, the thermal-fluidic cycle is outlined, and the requirements to generate capillary pressure in the condenser are discussed. The LHP design to fulfill the requirements is then described, and the experimental characterization of a single-condenser version of the LHP is reported. The thermal performance was dependent on the fan speed and the volume of the working fluid; a thermal resistance of $0.177^{\circ} \mathrm{C} / \mathrm{W}$ was demonstrated at a heat load of $200 \mathrm{~W}$, fan speed of $5000 \mathrm{rpm}$ and fluid volume of $67 \mathrm{~mL}$. When the LHP was filled with the working fluid to the proper volume, capillary pressure in the condenser was confirmed for all heat loads tested, with a maximum of $3.5 \mathrm{kPa}$ at $200 \mathrm{~W}$. When overfilled with the working fluid, the condenser was flooded with liquid, preventing the formation of capillary pressure and significantly increasing the LHP thermal resistance. This study provides the detailed thermal-fluidic considerations needed to generate capillary pressure in the condenser for controlling the condensation behavior and serves as the basis of developing multiplecondenser LHPs with low thermal resistance. [DOI: 10.1115/1.4025049]

Keywords: heat pipe, loop heat pipe, phase change, evaporation, condensation, aircooled heat sink

\section{Introduction}

Air-cooled heat sinks are the most widely adopted method for electronics cooling in various defense and commercial applications owing to the simplicity in implementation. Current designs, however, are limited in heat transfer performance due to the convective and conductive thermal resistance associated with the forced air-flow and the heat sink structure, respectively.

To address these challenges, we are developing an air-cooled heat sink that uses a novel LHP and an integrated multipleimpeller fan. A schematic of the heat sink is shown in Fig. 1. Heat enters at the base of the heat sink and is convectively removed from a stack of planar fins. A low profile motor mounted at the top of the device drives the fan, with the individual impellers interdigitated between the planar fins. Air is drawn from the top of the device into a central core and then flows radially across the fin surfaces. The convective heat transfer is enhanced by placing the impeller in close clearance with the heat transfer surfaces $(0.5 \mathrm{~mm})$, causing a constant shearing of the thermal boundary layer and inducing a locally turbulent-like flow pattern [1]. Furthermore, to reduce the conductive resistance, the entire heat sink structure is a LHP, with the base as the evaporator and the planar fins as the condensers. With this design, the thermal resistance of the heat sink can be decreased while achieving high heat removal with low fan power and a compact form factor [2]. Additionally, the interdigitated layout allows the heat sink to be constructed

${ }^{1}$ Present address: Combustion Research Facility, Sandia, 7011 East Avenue, Livermore, CA 94550.

${ }^{2}$ Corresponding author

Manuscript received February 2, 2013; final manuscript received April 27, 2013; published online October 25, 2013. Assoc. Editor: Hongbin Ma. with an appropriate number of condensers and impellers for the required heat removal. A ten-condenser heat pipe is projected to remove $1000 \mathrm{~W}$ using less than $33 \mathrm{~W}$ of electrical power, with a total thermal resistance of $0.05{ }^{\circ} \mathrm{C} / \mathrm{W}$ and a total heat sink size of a $102 \mathrm{~mm} \times 102 \mathrm{~mm} \times 102 \mathrm{~mm}[1,3]$.

Heat pipes are advantageous for integration in air-cooled heat sinks due to their low effective thermal resistance from the utilization of the latent heat of vaporization of a working fluid. In a conventional configuration, the fluid vaporizes from the surface of a microporous wick, which connects the evaporator and condenser sections and provides a flow path for liquid return to the evaporator using the capillary pressure at the evaporating meniscus [4-7]. A variation on these conventional heat pipes is the LHP, characterized by the separation of the evaporator and condenser and the absence of a wick in the condenser [8-10]. With only a wick in the evaporator, the viscous pressure drop is less in the LHP cycle and the condenser can be located meters away from the evaporator $[5,6,8,9]$. Furthermore, the evaporator and condenser can be independently designed for a particular application. Multipleevaporator LHPs have been developed for aerospace applications to cool several heat sources to the same temperature, and multiple-condenser LHPs have also been developed for a greater heat removal capacity [11-14]. Thus, the LHP configuration promises greater flexibility in application than that of traditional heat pipes and is utilized in this study to increase the surface area available at the condenser.

While the multiple condenser configuration of our LHP design offers benefits with the large area for cooling with minimal conductive resistance, the vertical stacking of the condensers at different heights will lead to unequal performance of the individual condensers in the presence of gravity. Neglecting the small 


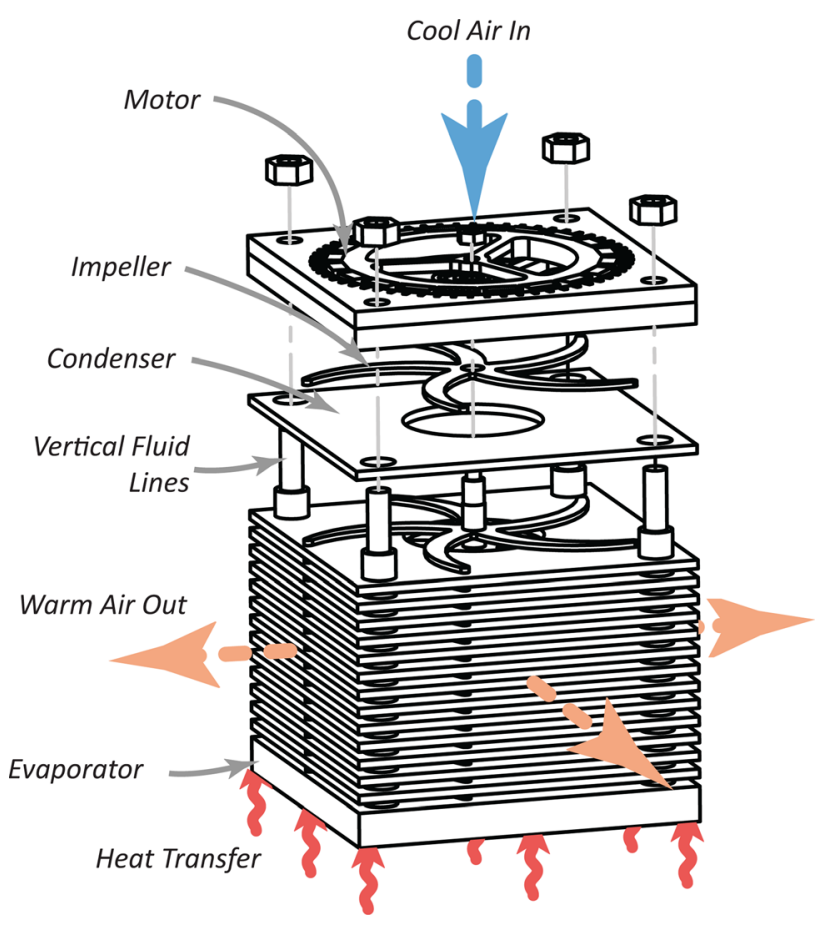

Fig. 1 Schematic of the air-cooled heat sink design. A LHP constitutes the fin structure. The bottom layer is the evaporator, and the remaining stacked array is the condensers. A lowprofile motor is mounted on top of the structure, driving a shaft that spins the impeller blades that rotate between the condensers. Rotation of the impellers draws ambient air from the top of the device, into a central core, and across the individual condensers for convective cooling.

viscous losses, the pressures in the vapor-side of the condensers are the same; however, the difference in the condenser heights leads to a gravitational pressure head in the liquid. The liquid pressure in the lower condenser(s) may exceed the vapor pressure and cause these condenser(s) to flood with liquid. When flooded, less surface area is available for condensation, and therefore the thermal resistance of the system increases. While dual-condenser LHPs have been developed in the past, most studies investigated operating conditions with the condensers at equal height or did not compare the performance of the individual condensers $[11,12,14]$.

To overcome the effect of gravity on the performance of the condensers, we designed the LHP with wicks in the condensers such that the capillary pressures associated with these wicks can compensate for differences in liquid pressure. Although the use of wicks in LHP condensers has been previously reported, the efforts have focused on different issues. For example, Kim and Peterson developed a reversible LHP with a condenser wick, but the wick was integrated as an alternate evaporator wick in the reverse operation [15]. Another study by Muraoka et al. reported flooded condenser wicks, with a liquid film on the wick surface [16]. To remove the liquid film and form a capillary meniscus at the wick surface, the heat pipe needs to operate with the appropriate liquid and vapor pressures.

This paper describes the development and characterization of a single-condenser version of the LHP with a wick in the condenser. The purpose of this study is to demonstrate the proper operation of the heat pipe cycle with generation of capillary pressure in the condenser. The thermal-fluidic cycle of the heat pipe and the requirements to form capillary pressure in the condenser are first detailed (Sec. 2). The design of the evaporator and condenser to meet these requirements as well as that of the integrated singlecondenser, air-cooled LHP are then described (Secs. 3 and 4). Finally, the experimental characterization of the LHP is reported; the startup characteristics as well as the thermal performance of the air-cooled LHP and its dependence on the fan speed and condenser capillary pressure are discussed. The effect of the filling volume of the working fluid is also described as it relates to the formation of capillary pressure and condensation behavior in the condenser. The development reported in this study serves as a step toward utilizing capillary pressure in the condensers to prevent flooding in multiple-condenser configurations.

\section{Thermal-Fluidic Cycle of the LHP}

The thermal-fluidic cycle of the single-condenser version of the LHP is shown in Fig. 2(a), and the temperatures and pressures of the cycle are shown schematically relative to the saturation curve in Fig. 2(b). Water is used as the working fluid due to its high latent heat of vaporization and surface tension. Heat enters the evaporator from the base and is conducted to the vapor channels inside the evaporator wick, where the liquid vaporizes at the

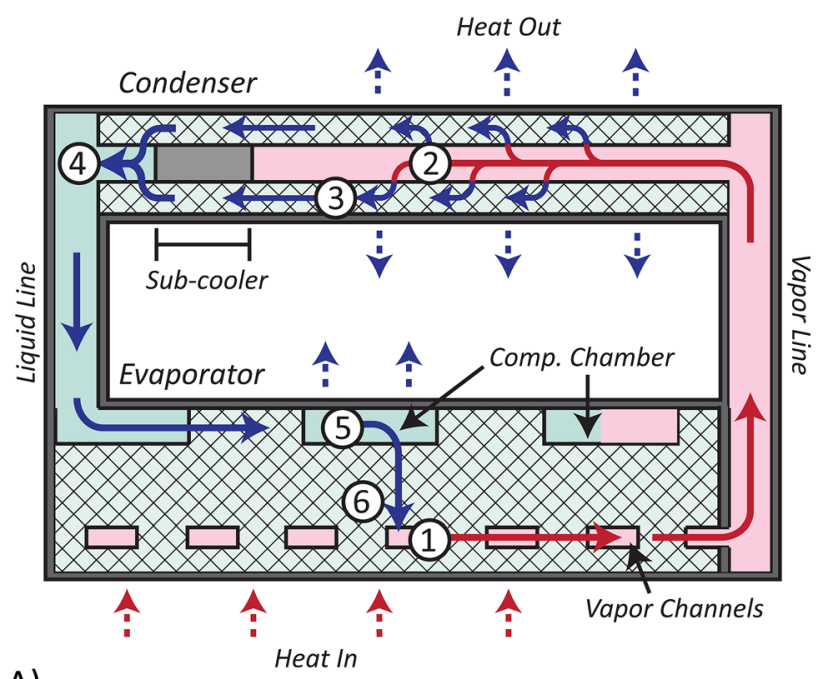

A)

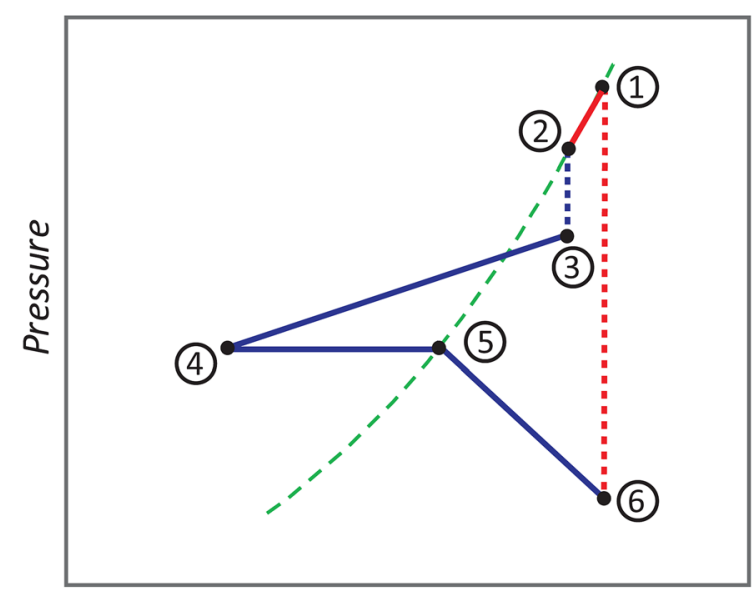

B)

Temperature

Fig. 2 Thermal-fluidic cycle of the LHP. A) Schematic of the heat pipe cycle. The hatched areas in the condenser and evaporator represent the wicks. The compensation chamber and vapor channels are interconnected network of channels at the top and bottom of the evaporator, respectively. B) Schematic of the pressure and temperature states of the cycle. The dashed sloped curve is the saturation curve, and the dotted vertical portions represent the capillary pressure differentials. 
channel surface (1). The vapor exits the evaporator through the channels, entering the vertical vapor line that connects to the condenser. A small pressure drop occurs due to viscous losses as the vapor travels from the evaporator to the condenser. The vapor then enters the planar condenser, where it is cooled by the air-flow on the outside of the condenser and condenses onto the surface of a wick that lines the inner surface of the condenser (2). A pressure differential is formed across the menisci of the condenser wick, which separates the vapor and liquid phases. Upon condensation, the liquid flows through the wick (3) toward the liquid-side of the condenser (4), undergoing a pressure drop and becoming subcooled due to the continued cooling. After exiting the condenser, the liquid enters the vertical liquid line and returns to the evaporator. The liquid enters the evaporator compensation chamber, which is the hottest location of the liquid side that does not have a wick and is at saturation (two-phase) (5). From the compensation chamber, the liquid flows through the evaporator wick to the vapor channels (6), where the cycle repeats. The liquid is metastable at a superheated state in the evaporator wick but does not vaporize due to the confinement of the pores. Additionally, although there are gradients in liquid pressure inside the wicks that results in a spatial variation in the menisci curvatures, in the descriptions that follow, the evaporator and condenser wicks will each be referred to having an average "meniscus." It is also useful to note that, in this single-condenser configuration, the height difference between the evaporator and condenser is small $(1 \mathrm{~cm})$ so that the effect of gravity is neglected. This simplification is in contrast to the effect of the gravitational pressure head expected in the multiple-condenser version but allows for the characterization of the condenser capillary pressure in a simplified format.

2.1 Requirements for Phase Separation in the Condenser. Flooding is prevented by separating the vapor and liquid phases at the condenser wick. The condenser and evaporator wicks separate the internal cavity of the heat pipe into two discrete volumes, the vapor side and liquid side. Accordingly, the two sides can have separate pressures due to the pressure discontinuities at the two wicks, determined by the saturation temperatures at the respective sides. The temperature of the two-phase region in the compensation chamber determines the liquid pressures of the heat pipe and influences the pressure differential across the condenser meniscus. Assuming negligible viscous pressure drop in the liquid line and negligible height difference between the condenser and evaporator, the capillary pressure in the condenser is determined as follows.

The pressures at (3) and (4) are dependent on the temperature at the compensation chamber, which is at saturation, through the relations

$$
\begin{gathered}
P_{4}=P_{5}=P_{\mathrm{SAT}}\left(T_{5}\right) \\
P_{3}=P_{4}+\Delta P_{\text {COND_WICK }}=P_{\mathrm{SAT}}\left(T_{5}\right)+\Delta P_{\text {COND_WICK }}
\end{gathered}
$$

where $\Delta P_{\text {COND wICK }}$ is the viscous pressure drop across the condenser wick and is a function of the pore structure and geometry of the condenser wick as well as the mass flow rate (heat load). Equation (2) shows that, for a given mass flow rate, the pressures at (3) and (4) are solely dependent on the compensation chamber saturation temperature when the liquid and vapor pressures are decoupled. The vapor pressure at the condenser can be related to the vapor pressure in the evaporator vapor channels through the viscous pressure drop ( $\left.\Delta P_{\mathrm{V} \_ \text {LINE }}\right)$ that occurs in the vapor line

$$
P_{2}=P_{1}-\Delta P_{\mathrm{V} \_ \text {LINE }}=P_{\mathrm{SAT}}\left(T_{1}\right)-\Delta P_{\mathrm{V} \_ \text {LINE }}
$$

Since $\Delta P_{\mathrm{V} \text { LINE }}$ is only a function of the vapor line geometry and mass flow rate, for a given heat load, the pressure at (2) is determined by the saturation temperature in the evaporator. However, the viscous pressure drop in the vapor line is small $(<100 \mathrm{~Pa})$ compared with the other pressure drops of the cycle, and therefore the vapor pressures in the condenser and evaporator are approximately equal. The pressure differential across the condenser wick meniscus $\left(\Delta P_{\text {COND_CAP }}\right)$ is therefore

$$
\begin{aligned}
& \Delta P_{\mathrm{COND} \_\mathrm{CAP}} \equiv P_{2}-P_{3} \\
& \Delta P_{\mathrm{COND} \_\mathrm{CAP}}=\left[P_{\mathrm{SAT}}\left(T_{1}\right)-\Delta P_{\mathrm{V} \_ \text {LINE }}\right] \\
&-\left[P_{\mathrm{SAT}}\left(T_{5}\right)+\Delta P_{\mathrm{COND} \text { WICK }}\right] \\
& \Delta P_{\mathrm{COND} \_\mathrm{CAP}}= {\left[P_{\mathrm{SAT}}\left(T_{1}\right)-P_{\mathrm{SAT}}\left(T_{5}\right)\right] } \\
&-\Delta P_{\mathrm{V} \_ \text {LINE }}-\Delta P_{\mathrm{COND} \text { WICK }}
\end{aligned}
$$

Equation (6) shows that the formation of a positive pressure differential (a receding meniscus, where the liquid is concave in the pore) in the condenser requires the saturation temperature of the vapor channels (1) to be sufficiently higher than the saturation temperature in the compensation chamber (5). While an advancing meniscus (where the liquid is convex into the vapor) can also be used to prevent condenser flooding, a preliminary experimental study on the capillary pressure of sintered metal powder wicks showed that the receding meniscus is capable of sustaining significantly higher capillary pressures than the advancing meniscus in the same wick [17]. Thus, we designed for the case of a receding meniscus in the condenser, which requires the compensation chamber to be cooled below the temperature of the vapor channels and, therefore, requires a thermal gradient across the evaporator wick.

\section{Evaporator and Condenser Design}

The evaporator and condenser were designed to establish the appropriate vapor and liquid pressures to form capillary pressure in the condenser (Eq. (6)) and to minimize the total thermal resistance of the air-cooled LHP. Figure 3 shows the key internal features of the evaporator and condenser, as well as the circulation path of the water. For material compatibility with water, both components were constructed using copper or Monel 400 [18-21].

3.1 Evaporator. The evaporator has a footprint of $102 \mathrm{~mm} \times 102 \mathrm{~mm}$ and height of $17.5 \mathrm{~mm}$ and utilizes a threelayer wick structure (Fig. 3). For efficient heat transfer from the base to the vapor channels, the vapor channels are constructed in a high thermal conductivity wick (wick 1), which is attached to the base (solid copper) for direct thermal contact. This wick needs to supply the capillary pressure for circulating the working fluid. To maintain a thermal gradient between the vapor channels and the compensation chamber, the vapor channels are separated from the compensation chamber by a low thermal conductivity wick (wick 2). To effectively utilize the convective cooling at the top of the evaporator, the compensation chamber is surrounded by a highpermeability wick that thermally connects the liquid in the compensation chamber to the evaporator top (wick 3). This wick also provides a path for the liquid to spread across the compensation chamber area when sections are blocked by the presence of vapor.

The expected temperature profile in the evaporator is shown in Fig. 4 for operation at $1000 \mathrm{~W}$ and a base temperature of $80^{\circ} \mathrm{C}$. The thermal modeling was performed with finite element software, COSMOL Multiphysics, by solving the steady-state energy and Darcy equations for the temperatures and pressures, respectively. The base temperature was set to $80^{\circ} \mathrm{C}$, and the temperature of the vapor channel was iteratively adjusted so that the heat transfer through the base was $1000 \mathrm{~W}$, which resulted in a vapor temperature of $77.2^{\circ} \mathrm{C}$. The top surface was modeled with convective heat transfer coefficient of $146 \mathrm{~W} /\left(\mathrm{m}^{2} \mathrm{~K}\right)$, which was expected for a fan speed of $5000 \mathrm{rpm}$ [1], with a exponential radial increase in the air temperature from room temperature at $30^{\circ} \mathrm{C}$ to $50^{\circ} \mathrm{C}$. The wick was modeled as layers of sintered metal wicks, where a fine (5-15 $\mu \mathrm{m}$, particle diameter) copper wick was used for the vapor channel wick (wick 1), a Monel 400 wick $(<44 \mu \mathrm{m})$ was used for 


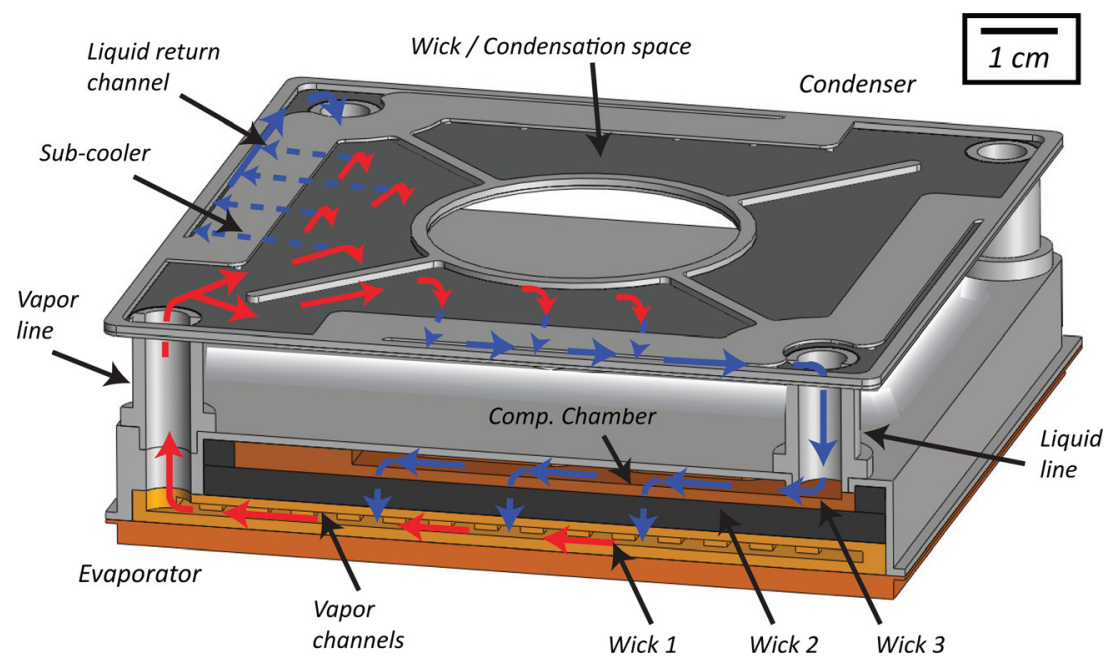

Fig. 3 Schematic representation of the integrated single-condenser LHP, showing the key design features of the evaporator and condenser through cross-sections perpendicular and parallel, respectively, to the plane of the evaporator base. The evaporator utilizes a three-layer wick, consisting of a high thermal conductivity and capillary pressure wick at the base (wick 1), a low thermal conductivity wick (wick 2), and a high permeability wick (wick 3). The condenser consists of three regions: the central condensation space, the subcooler, and the liquid return channel.

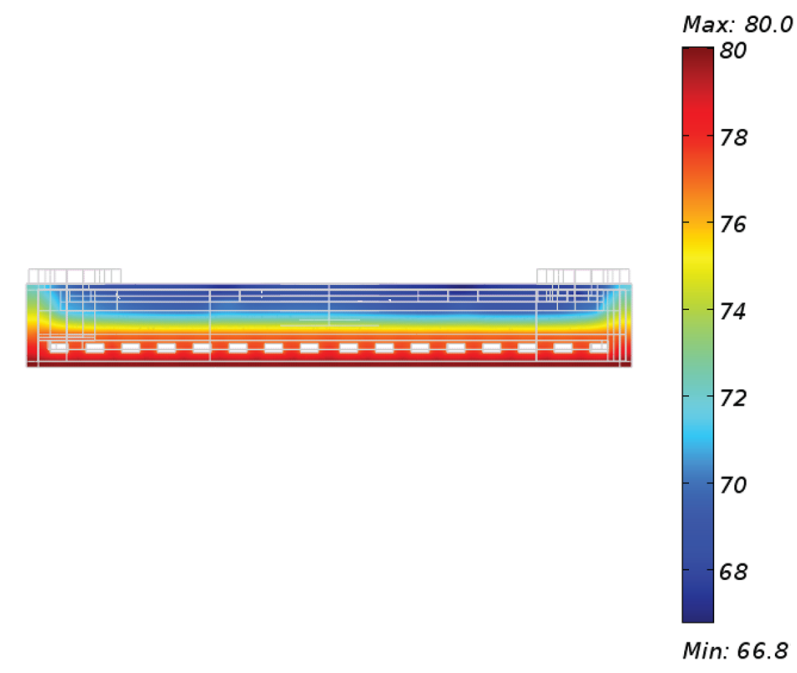

Fig. 4 Expected temperatures $\left({ }^{\circ} \mathrm{C}\right.$ ) for operation with a $1000-\mathrm{W}$ heat load and a base temperature of $80^{\circ} \mathrm{C}$, at a cross-section $3 \mathrm{~cm}$ away from the edge of the evaporator. A significant fraction of the thermal gradient is maintained across the insulating wick layer. Modeling was performed with COSMOL Multiphysics.

the insulating wick (wick 2), and a coarse $(45-70 \mu \mathrm{m})$ copper wick was used for the high permeability wick (wick 3 ). The properties of the wicks are listed in Table 1 . The outer frame was modeled as Monel 400 with a thermal conductivity of $20 \mathrm{~W} /(\mathrm{m}-\mathrm{K})$. The insulating wick impedes the conduction from the base of the evaporator to the top and establishes a thermal gradient in the wick structure, such that the hottest temperature in the compensation chamber is $6.5^{\circ} \mathrm{C}$ lower than the vapor temperature. This temperature difference is used to establish capillary pressure in the condenser through Eq. (6). For this design, the total internal volume of the evaporator is calculated to be $54.8 \mathrm{~mL}$, with the vapor region and the compensation chamber accounting for 6.9 and $5.6 \mathrm{~mL}$, respectively. Figure 5 shows the features in a crosssectional image of a prototype evaporator. The details of the mod-
Table 1 Wick properties

\begin{tabular}{lcccc}
\hline \hline $\begin{array}{l}\text { Wick } \\
\text { material }\end{array}$ & $\begin{array}{c}\text { Powder } \\
\text { size }(\mu \mathrm{m})\end{array}$ & $\begin{array}{c}\text { Thermal conductivity } \\
(\mathrm{W} /(\mathrm{m}-\mathrm{K}))\end{array}$ & $\begin{array}{c}\text { Permeability } \\
\left(\mathrm{m}^{2}\right)\end{array}$ & $\begin{array}{c}\text { Capillary } \\
\text { pressure }(\mathrm{kPa})\end{array}$ \\
\hline Copper & $5-15$ & 69 & $0.96 \times 10^{-13}$ & 72 \\
Monel 400 & $<44$ & 2.4 & $1.5 \times 10^{-12}$ & 18.7 \\
Copper & $40-75$ & 27.5 & $1.9 \times 10^{-11}$ & 12.4 \\
\hline \hline
\end{tabular}

Note: Most of the measurements were taken by Domínguez Espinosa through collaboration [25], and the sintering procedure and measurement method for each of the properties are detailed in Refs. [22,25]. The capillary pressure given is for the case with a receding meniscus.

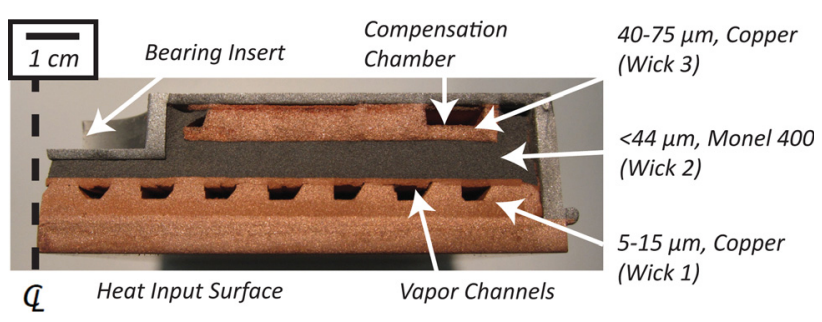

Fig. 5 Cross-sectional image of a prototype evaporator, showing the three-layer sintered wick structure. The centerline of the evaporator is shown; an insert is made in the evaporator frame for the impeller shaft bearing. The insulating wick $(<44 \mu \mathrm{m}$, Monel 400 ) separates the vapor channels and compensation chamber, which are formed as channels within the high conductivity (5-15 $\mu \mathrm{m}$, copper) and high permeability (40-75 $\mu \mathrm{m}$, copper) wicks, respectively.

eling, geometrical specifications, and fabrication can be found in Refs. [22].

3.2 Condenser. A thin, planar geometry was adopted for the condenser $(102 \mathrm{~mm} \times 102 \mathrm{~mm} \times 2.5 \mathrm{~mm})$ to reduce the volume occupied for a given surface area (Fig. 6). A wick covers the inner surface of the condenser, and the vapor (condensation space) and liquid regions are separated by a partition. As shown in Fig. 2, upon condensation, the liquid flows through the wick across this partition to enter the liquid return channel and exit the condenser. Because of the continued cooling, the liquid is subcooled as it 

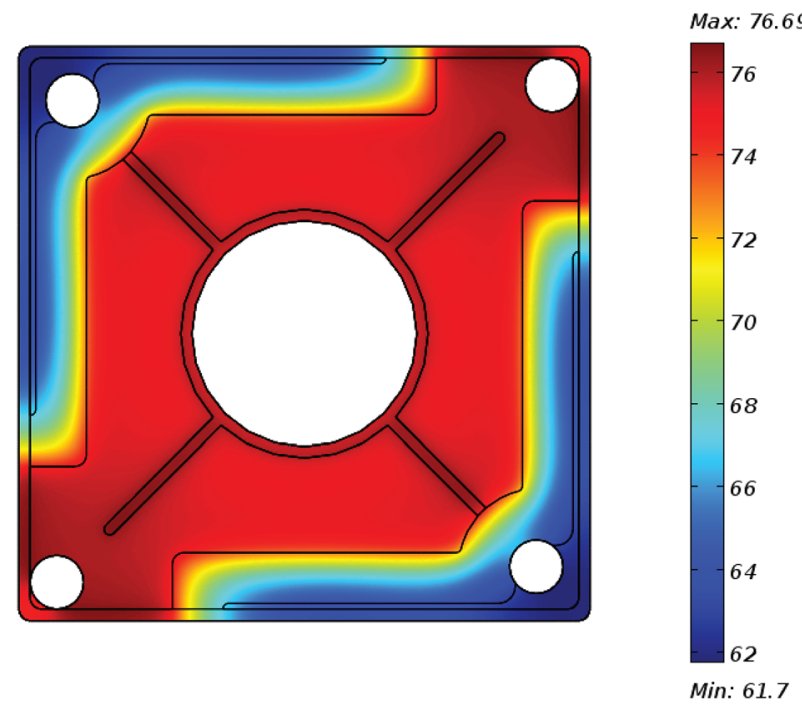

Fig. 6 Expected temperatures $\left({ }^{\circ} \mathrm{C}\right)$ on the outer surface of the condenser. The central, condensation space is uniform in temperature, while a significant thermal gradient occurs across the subcooler regions. Total heat removed per condenser face is $61.5 \mathrm{~W}$ for the modeled case. Modeling was performed with COSMOL Multiphysics.

flows across the partition (subcooler), which prevents the liquid from flashing inside of the wick [22,23]. The condensation space is maximized by locating the partition toward the edges of the condenser. A larger condensation area facilitates the convective cooling by maintaining a larger isothermal area at the hotter vapor temperature.

The predicted temperature profile of the outer surface of the condenser is shown in Fig. 6. Modeling was performed with COSMOL Multiphysics for a vapor temperature of $77.2^{\circ} \mathrm{C}$ and a convective boundary condition of $146 \mathrm{~W} /\left(\mathrm{m}^{2}-\mathrm{K}\right)$, which is expected for a fan speed of $5000 \mathrm{rpm}$ [1]. As in the analysis of the evaporator, the energy, and Darcy equations were numerically solved. The air temperature was modeled with the same approach as that for the evaporator. The thermal conductivities of the wick (sintered Monel $400,<44 \mu \mathrm{m}$ particle diameter) and metallic frame (Monel 400) are 2.4 and $20 \mathrm{~W} /(\mathrm{m}-\mathrm{K})$, respectively. Because of the use of a thin frame and wick, the temperature drop between the condensation area and the outer surface of the condenser is small $\left(0.6-2.5^{\circ} \mathrm{C}\right)$. The total internal volume of the condenser is $6.2 \mathrm{~mL}$ with $2.6 \mathrm{~mL}$ in the vapor/condensation space. Figure 7 shows the features in a symmetric half of a fabricated condenser; two identical halves are joined to complete a condenser. The details of the modeling, geometrical specifications, and fabrication can be found in Ref. [23].

\section{Experimental Setup}

Figure 8 shows the LHP (evaporator and condenser) combined with a motor and fan assembly to construct a heat sink. The impellers are $100 \mathrm{~mm}$ and $6.93 \mathrm{~mm}$ in diameter and thickness, respectively, with an average clearance of $0.5 \mathrm{~mm}$ from the heat transfer surfaces [1], which include two faces of the condenser and the top surface of the evaporator. Four machined Monel 400 tubes were used for the vapor (2) and liquid (2) lines. The condenser was attached to the liquid and vapor lines with a copper-silver braze $(72 \% \mathrm{Cu} / 28 \% \mathrm{Ag})$, and this assembly was subsequently attached to the evaporator with a gold-tin braze $(80 \% \mathrm{Au} / 20 \% \mathrm{Sn})$. The brazes were selected such that the brazing temperature does not exceed the previous sintering temperatures in the evaporator and condenser. A custom jig was used during brazing to correctly align the components. Leaks from the brazing process were repaired by soldering $(63 \% \mathrm{Sn} / 37 \% \mathrm{~Pb})$. The total volume of the

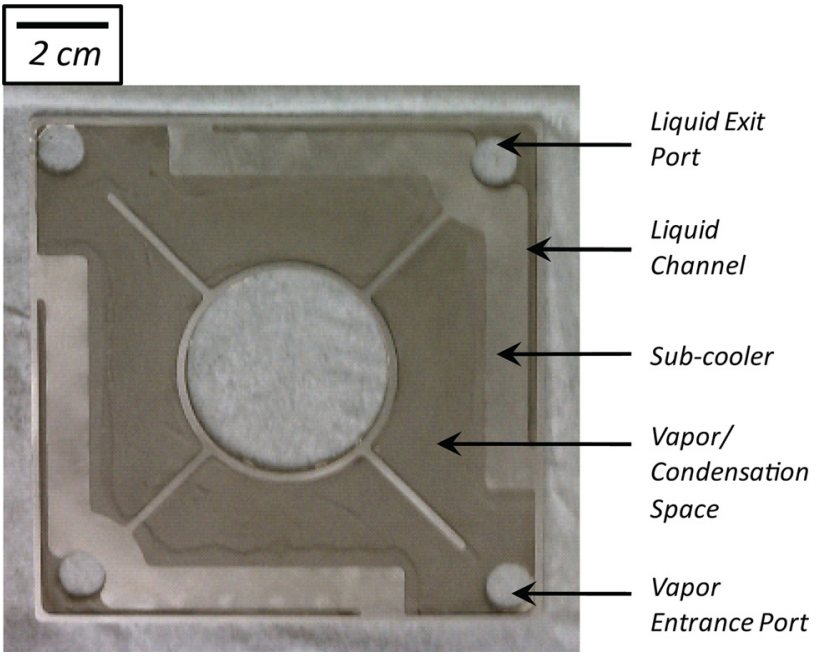

Fig. 7 Image of a symmetric half of a condenser. The vapor ports access the central vapor/condensation space, and the liquid ports connect to the liquid return channels. The subcooler is shown as a partition between the vapor and liquid regions.

heat pipe was calculated to be $88.1 \mathrm{~mL}$, with a liquid space volume of $75 \mathrm{~mL}$.

Figure $8(b)$ shows the entire experimental apparatus, which also includes a manifold for filling the heat pipe with water. The four-pronged manifold was constructed from copper tubing and compression tube connectors to mate the LHP to a heat pipe filling station. The filling manifold was instrumented with sensors and attached to the four pipes that extended from the LHP. The layout of the instrumentation is shown schematically in Fig. 9, and the locations and specifications of the sensors are given in Table 2. Two pressure transducers were installed in the manifold to measure the liquid and vapor pressures, and T-type thermocouples were used to monitor the surface temperatures of the liquid and vapor lines as well as the air temperature. The vapor temperature was measured in the manifold with a thermistor probe. The measurements were recorded using a data-acquisition board (NI USB6251, SCB-68; National Instruments), interfaced with data-acquisition/control software (LabVIEW 8.5; National Instruments). The heat load was applied to the evaporator by a copper heater block (footprint of $101.6 \mathrm{~mm} \times 101.6 \mathrm{~mm}$, thickness of $15.9 \mathrm{~mm}$ ) with four embedded $48 \pm 0.3 \Omega$ cartridge heaters $(6.35 \mathrm{~mm}$ diameter, $76.2 \mathrm{~mm}$ length) connected in parallel for a total resistance of 12.1 $\Omega$ (35025K133, McMaster-Carr). The heater block was placed in an insulating polytetrafluoroethylene block to minimize heat loss to the environment.

4.1 Tested Parameters. The experimental characterization of the LHP was performed to investigate (1) the thermal resistance from the vapor temperature to the ambient air temperature, (2) the state of the meniscus in the condenser (capillary pressure), and (3) the effects of the filling volume on heat pipe performance.

The thermal resistance of the air-cooled LHP was quantified using the vapor and ambient air temperatures. Because of the thin condenser construction, the vapor temperature inside the condenser was estimated to be the condenser surface temperature. The characterization of the state of the condenser meniscus was performed primarily through liquid and vapor pressure measurements.

During the experiments, the heat load was varied from 80 to $200 \mathrm{~W}$, and the fan speed from 3300 to $5000 \mathrm{rpm}$, and the liquid filling volume of water from 63 to $81 \mathrm{~mL}$ to determine the proper filling range. Underfilling can lead to insufficient liquid in the liquid-side of the LHP, and overfilling can result in unwanted liquid in the vapor-side. When testing the effects of the filling volume, the fan speed was set to a baseline of $4200 \mathrm{rpm}$. 


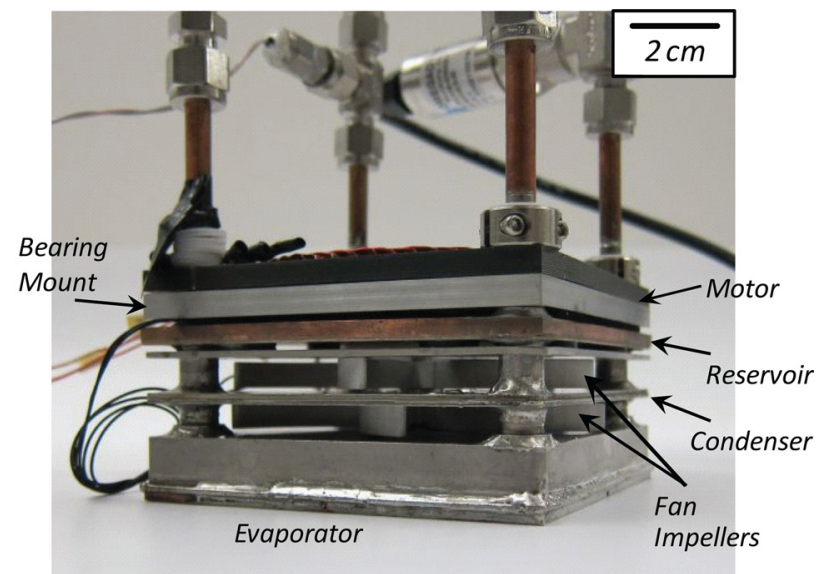

A)

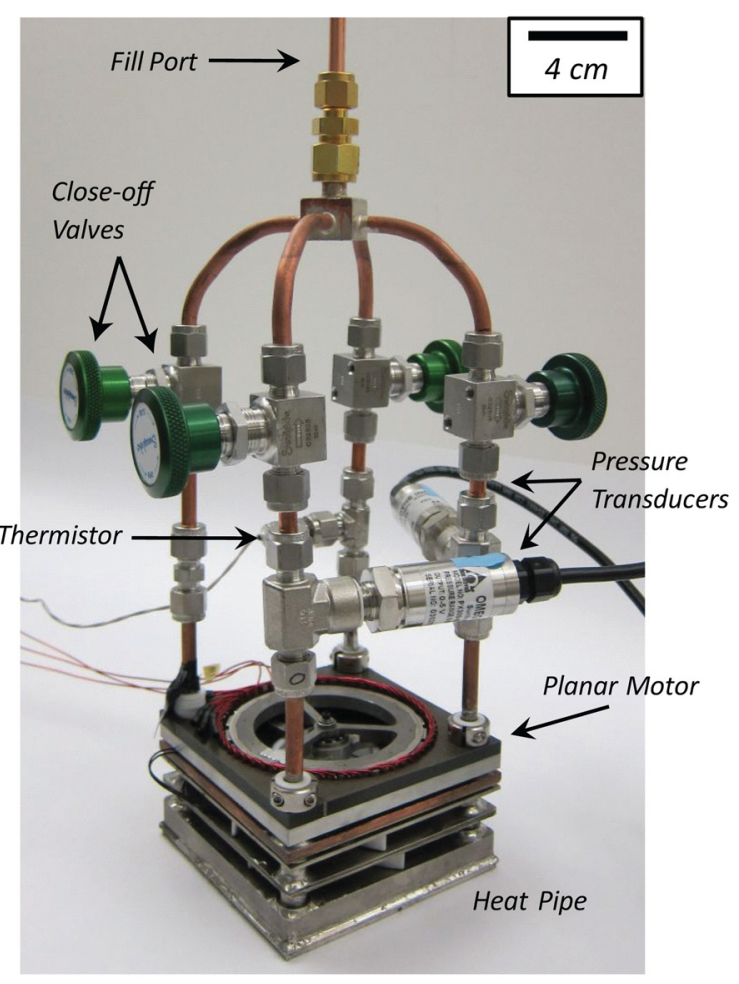

B)

Fig. 8 Experimental setup. (a) Single-condenser LHP. The condenser and the top surface of the evaporator are cooled with two impellers. The reservoir was added for possible operation as a capillary pumped loop; this was not tested in this study. (b) Single-condenser LHP with the instrumented filling manifold. Two pressure transducers and a thermistor measure the vapor and liquid pressures and the vapor temperature, respectively. The four valves on the manifold allow the LHP to be isolated from the filling station for testing.

\section{Results and Discussion}

5.1 Startup. The LHP was started by applying heat to the evaporator, and Fig. 10 shows the startup behavior from room temperature. The vapor pressure and the liquid pressure at the compensation chamber (raw data) are plotted as a function of time for a stepped heat input. Prior to startup, the liquid pressure is higher than the vapor pressure due to the gravitational pressure head. The initial delay in the rise of the vapor pressure $(\sim 20 \mathrm{~s})$ is likely due to the transient heating of the evaporator. The LHP was considered to fully start when the liquid pressure began to rise ( 200 s), which is indicative of circulation of the working fluid.

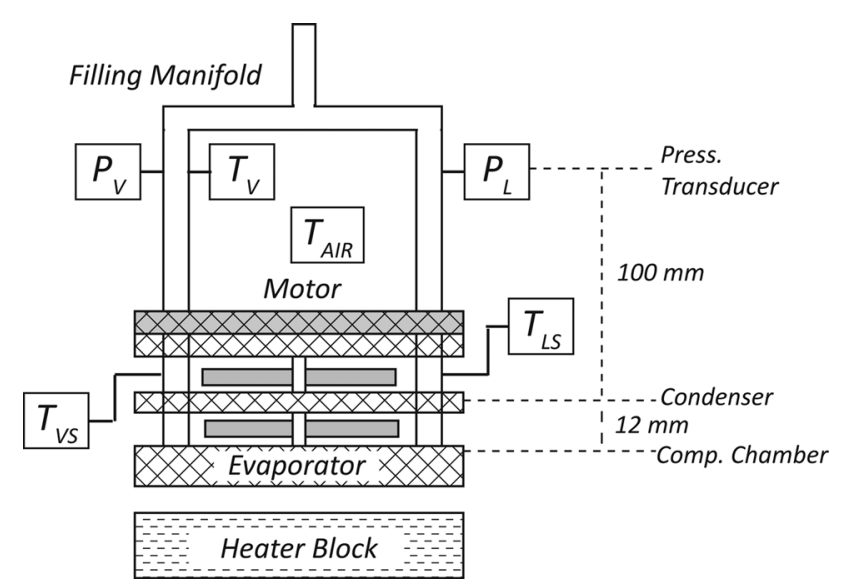

Fig. 9 Schematic representation of experimental instrumentation. " $P$ " and " $T$ " indicate pressure and temperature measurements, and " $V$ ", " $L$," and " $S$ " indicate vapor, liquid, and surface measurements, respectively. The liquid pressure was obtained $100 \mathrm{~mm}$ above the condenser and $112 \mathrm{~mm}$ above the compensation chamber in the evaporator. The liquid pressures at the respective locations were calculated by adding the appropriate hydrostatic heads to the measured pressures.

For the heat loads shown, steady state was achieved in approximately $30 \mathrm{~min}$. Although the minimum heat load required for startup was not investigated, successful startup was observed for any heat load larger than $75 \mathrm{~W}$.

5.2 Heat Removal Performance. The heat removal performance of the LHP was evaluated by measuring the vapor temperature at different heat loads. Figure 11 shows the difference between the vapor and ambient temperatures as a function of the heat load for different fan speeds. The ambient temperature was subtracted from the vapor temperature to compensate for the change in environmental conditions during testing. The fluctuation of the ambient air temperature was between 19.8 and $21^{\circ} \mathrm{C}$ with a median of $20.5^{\circ} \mathrm{C}$.

The temperature difference increases linearly with increasing heat load, indicating a constant thermal resistance. The slopes of the data can be approximated as the average convective resistances since negligible temperature drop occurs between the vapor and the condenser surface temperatures. The convective resistance decreases from 0.233 to $0.177^{\circ} \mathrm{C} / \mathrm{W}$ as the fan speed increases from 3300 to $5000 \mathrm{rpm}$, going below the thermal resistance of the current state-of-the-art air-cooled heat sink, $0.2^{\circ} \mathrm{C} / \mathrm{W}$ [24]. Higher fan speeds result in lower resistance due to a higher convective heat transfer coefficient and an increase in air flow rate, which decreases the temperature rise of the air as it passes across the condenser surface.

5.3 Phase Separation. The functionality of the condenser wick and the control of the vapor and liquid pressures were evaluated by measuring the respective pressures at various heat loads. Figure 12 shows the measured differences between the vapor and liquid pressures in the condenser as a function of the heat load and fan speed. The capillary pressure in the condenser, $\Delta P_{\text {CAP_COND }}$, is determined as

$$
\Delta P_{\mathrm{CAP} \_\mathrm{COND}}=\left(P_{V}-P_{L}\right)-\Delta P_{\mathrm{COND} \_ \text {WICK }}
$$

where $P_{V}, P_{L}$, and $\Delta P_{\text {COND_wICK }}$ are the measured vapor and liquid pressures in the condenser and the viscous pressure drop through the condenser wick, respectively. A positive $\Delta P_{\text {CAP_COND }}$ corresponds to a receding meniscus in the condenser wick. $\Delta \mathrm{P}_{\mathrm{COND} \text { wICK }}$ was obtained for a given mass flow rate (heat load) using an experimentally determined relation for the permeability 
Table 2 Mounting location and specifications of the sensors

\begin{tabular}{lcc}
\hline \hline Measurement & Location & Model, manufacturer \\
\hline Vapor/liquid pressure & Manifold & Pax. uncertainty \\
Vapor temperature & Manifold & TH-10-44006-1/8-2-40, Omega Eng. \\
Vapor/liquid line surface temp. & On tube, above condenser & 5TC-TT-T-40-36, Omega Eng. \\
Ambient air temperature & Air inlet & 5TC-TT-T-40-36, Omega Eng. \\
\hline \hline
\end{tabular}

Note: The pressure transducers (linear output, $0-5 \mathrm{~V}$ ) were calibrated at two states, at vacuum (nominally $0 \mathrm{kPa}$ ) and atmospheric $(101.33 \mathrm{kPa})$ pressures. With this calibration, the measurement error was approximately linear with pressure, ranging from $0.05 \mathrm{kPa}$ to $0.3 \mathrm{kPa}$ from $5 \mathrm{kPa}$ to atmospheric pressures, respectively. As both pressure transducers were calibrated together, the two measurements were within $0.01 \mathrm{kPa}$ and $0.2 \mathrm{kPa}$ of each other at $5 \mathrm{kPa}$ and atmospheric pressures, respectively. The vapor temperature referenced in the later discussions is the saturation temperature derived from the vapor pressure measurement, since the accuracy from the pressure measurement is greater (maximum $0.1^{\circ} \mathrm{C}$ ) than that of the vapor temperature measurement in the manifold. The uncertainty of the vapor temperature measurement with the thermistor (TH-10-44006-1/8-2-40) was obtained from the manufacturer, and those for the thermocouples (5TC-TT-T-40-36) were measured by a precision temperature-controlled water bath for a range of temperatures from $20^{\circ} \mathrm{C}$ to $70^{\circ} \mathrm{C}$.

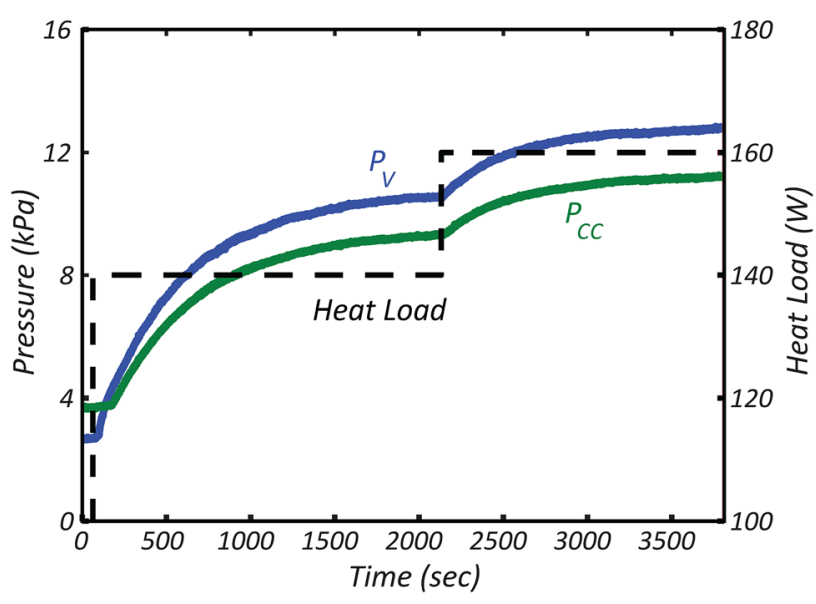

Fig. 10 Startup characteristics of the LHP showing the vapor and liquid pressures plotted as a function of time, at a fan speed of 4200 RPM. The applied heat load (dashed) is also shown schematically for reference (right axis).

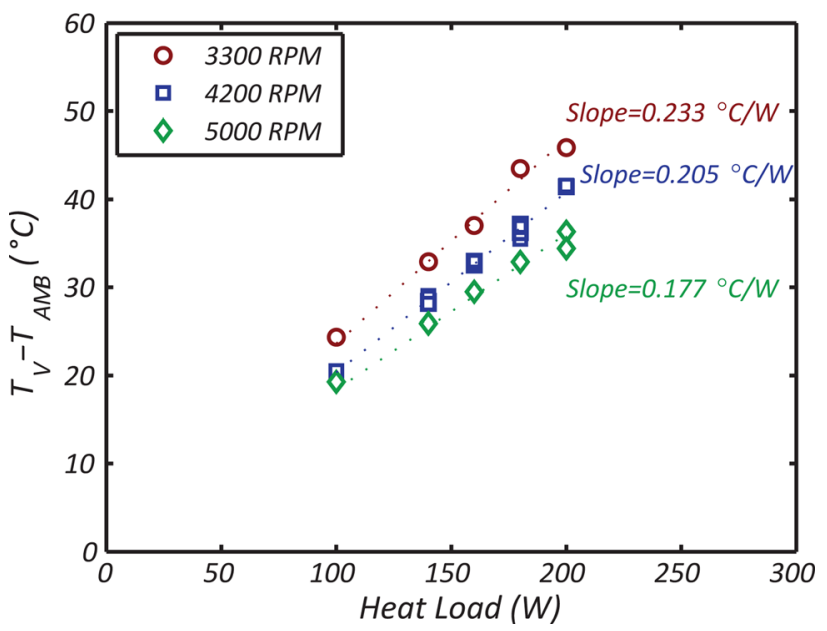

Fig. 11 Temperature difference between the vapor and ambient air plotted against heat load for different fan speeds. Data for $\mathbf{3 3 0 0}$ and $\mathbf{5 0 0 0} \mathrm{rpm}$ were taken at a working fluid filling volume of $67 \mathrm{~mL}$ and data for $4200 \mathrm{rpm}$ includes the volumes of 63,65 , and $67 \mathrm{~mL}$. The dotted lines are linear fits to the data, and the slopes of these fits are shown.

of the condenser wick [23], and this calculated value is plotted separately in Fig. 12. A receding meniscus was formed for all of the heat loads tested, which confirms phase separation in the condenser and the presence of a thermal gradient in the evaporator wick.

Journal of Thermal Science and Engineering Applications

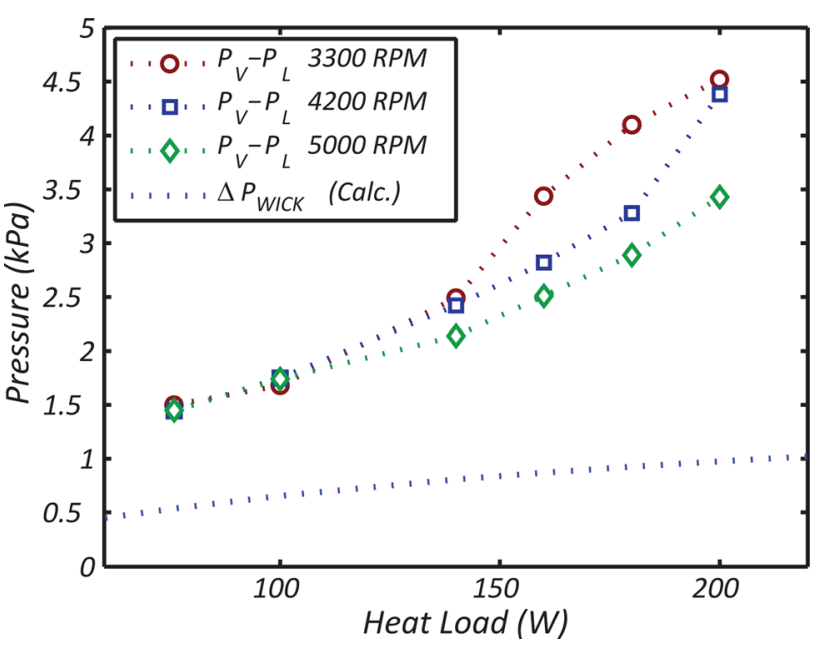

Fig. 12 Pressure difference as a function of the heat load for different fan speeds. The dotted line indicates the expected pressure drop across the condenser wick. The (receding) capillary pressure is the difference between the vapor-liquid pressure difference (experimental data) and the pressure drop across the wick (calculated predictions). Data for 3300 and $5000 \mathrm{rpm}$ were taken at the filling volume of $67 \mathrm{~mL}$; data for 4200 rpm were taken at $69 \mathrm{~mL}$.

The capillary pressure increased with heat load, with a maximum of $3.5 \mathrm{kPa}$ at $3300 \mathrm{rpm}$ and $200 \mathrm{~W}$, due to an increase in the saturation pressure difference between the compensation chamber and the vapor channels (locations 5 and 1 in Fig. 2, respectively). This trend can be explained as follows. Conduction from the base of the evaporator, through the wick and to the convectively cooled top, determines the compensation chamber temperature relative to the vapor channel temperature. The difference of these temperatures results in a saturation pressure difference, which consequently determines the condenser capillary pressure (Eq. (6)). The capillary pressure increases with heat load due to the increased heat transfer across the evaporator and the corresponding increase in the temperature difference between the vapor channels and the compensation chamber. Similarly, this temperature difference is greater at lower fan speeds due to the decreased cooling at the top surface of the evaporator, resulting in higher capillary pressure. Furthermore, the capillary pressure increase is greater at higher temperatures due to the increased slope of the saturation curve $(d P / d T)_{\mathrm{SAT}}$; this effect can be observed in Fig. 12 in the higher slopes at increased heat loads.

5.4 Effect of Filling Volume on Heat Pipe Performance. The proper liquid filling volume of LHPs depends on the size of the liquid-side volume and needs to account for thermal expansion of the working fluid at the highest expected operating temperature. 


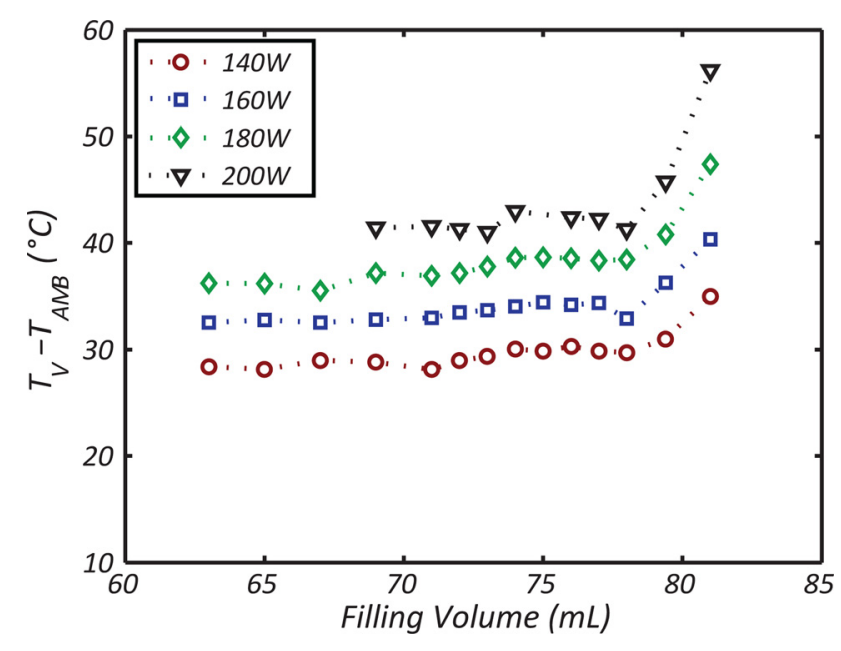

Fig. 13 Temperature difference between the vapor and ambient air plotted as a function of the filling volumes for varying heat loads. Data were taken at a fan speed of $4200 \mathrm{rpm}$.

To compensate for the expansion, the LHP should be filled below the liquid-side volume by a prescribed amount, which results in vapor in the two-phase region of the compensation chamber. Figure 13 shows the temperature difference between the vapor and ambient as a function of filling volume and heat load, for operation at $4200 \mathrm{rpm}$. For a given heat load, the temperature difference represents the thermal resistance. Different heat loads are shown to indicate operation at different temperatures.

The temperature difference does not substantially change for filling volumes between 63 and $78 \mathrm{~mL}$ but increases with filling volumes greater than $78 \mathrm{~mL}$. The constant thermal resistance is maintained as the compensation chamber compensates for different levels of underfilling by adjusting the size of the vapor region. However, the large range of filling volumes with constant thermal resistance $(15 \mathrm{~mL})$ is not consistent with the size of the compensation chamber $(5.6 \mathrm{~mL})$. We speculate that the LHP was functional at the lower filling volumes due to vapor occupying one of the liquid lines, thus extending the effective volume allowed for the compensation chamber. The underfilling is minimized at $78 \mathrm{~mL}$, which approximately matches the calculated LHP liquid volume of $75 \mathrm{~mL}$. A possible explanation for the volume difference is the presence of condensed liquid in the cooler ends of the vapor lines.

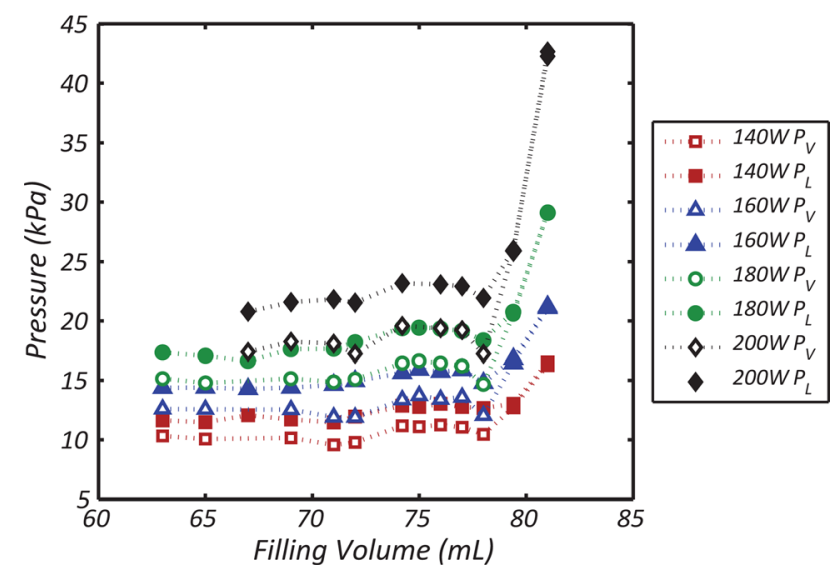

Fig. 14 Vapor and liquid pressures, plotted as a function of filling volume. The subscripts " $V$ " and " $L$ " indicate vapor and liquid, respectively. The vapor and liquid pressures are equal when the heat pipe is flooded $(>78 \mathrm{~mL})$. Data were taken at a fan speed of $4200 \mathrm{rpm}$.
The increase in temperature difference after $78 \mathrm{~mL}$ indicates overfilling, where liquid occupies not only the allocated liquidside of the LHP but also a portion of the vapor space in the condenser. As a result, the condenser floods and the area available to the vapor for condensation decreases. The LHP, therefore, operates with a higher vapor temperature to condense the mass flow associated with the same heat load. For a given overfilled volume, the increase in the temperature difference is more pronounced at higher heat loads due to the greater volume expansion of the liquid from the higher operating temperatures.

Figure 14 shows the vapor and liquid pressures plotted as a function of filling volume for different heat loads. A pressure difference between the vapor and liquid is maintained for the underfilled volumes up to $78 \mathrm{~mL}$. However, for filling volumes greater than $78 \mathrm{~mL}$, the pressures become equal. When the heat pipe is overfilled, vapor-liquid phase separation does not occur across the wick surface, and the flooded condenser wick does not have a stable meniscus.

\section{Conclusions}

A novel LHP with a wick structure in the condenser was developed to accommodate for the use of multiple condensers in a vertically stacked configuration. A single-condenser version of this LHP was constructed, and the thermal performance and the functionality of the condenser wick were characterized. The wick is utilized in the condenser to separate the vapor and liquid across a capillary meniscus, decoupling the vapor and liquid pressures. The evaporator utilizes a multilayer wicking structure to provide high capillary pumping pressure and different local thermal conductivities. When the LHP was properly filled with the working fluid (water) to less than $78 \mathrm{~mL}$, a thermal resistance as low as $0.177^{\circ} \mathrm{C} / \mathrm{W}$ was observed at a fan speed of $5000 \mathrm{rpm}$. In addition, capillary pressures of up to $3.5 \mathrm{kPa}$ were demonstrated in the condenser, confirming successful phase separation and the potential for utilizing wicks in the condenser for multiple-condenser LHPs. However, filling volumes greater than $78 \mathrm{~mL}$ resulted in condenser flooding, which was characterized by the increase in thermal resistance and the loss of capillary pressure in the condenser. This study demonstrates vapor-liquid pressure separation in a LHP by the integration of a wick in the condenser as a possible mechanism of utilizing multiple condensers for high surface area heat sinks.

\section{Acknowledgment}

The experimental system was constructed through the effort of multiple collaborators at Massachusetts Institute of Technology: the planar motor was designed by David Jenicek and Professor Jeffery Lang and fabricated by Ari Umans; the motor controller was developed by Kai Cao. This work was supported by the Defense Advanced Research Projects Agency (DARPA) Microsystems Technology Office (MTO) Microtechnologies for Air-Cooled Exchangers (MACE) program, Grant No. W31P4Q09-1-0007, with Dr. Thomas Kenny and Dr. Avram Bar-Cohen as the program managers.

\section{Nomenclature}

$$
\begin{aligned}
P & =\text { pressure }(\mathrm{kPa}) \\
\Delta P & =\text { pressure drop }(\mathrm{kPa}) \\
P_{\mathrm{SAT}}(T) & =\text { saturation pressure at temperature } T(\mathrm{kPa}) \\
T & =\text { temperature }\left({ }^{\circ} \mathrm{C}\right)
\end{aligned}
$$

\section{Subscripts}

$\mathrm{AMB}=$ ambient air

COND_CAP $=$ condenser capillary pressure

COND_WICK $=$ condenser wick

$$
\begin{aligned}
& L=\text { liquid } \\
& V=\text { vapor }
\end{aligned}
$$




\section{References}

[1] Staats, W. L., 2012, "Active Heat Transfer Enhancement in Integrated Fan Heat Sinks," Ph.D. thesis, Massachusetts Institute of Technology, Cambridge, MA.

[2] Peters, T. B., Mccarthy, M., Allison, J., Domínguez Espinosa, F. A., Jenicek, D., Kariya, H. A., Staats, W. L., Brisson, J. G., and Wang, E. N., 2012, "Design of an Integrated Loop Heat Pipe Air-Cooled Heat Exchanger for High Performance Electronics," IEEE Trans. Compon., Packag., Manuf. Technol., 2(10), pp. 1637-1648.

[3] Kariya, H. A., Staats, W. L., Hanks, D. F., Peters, T. B., Cleary, M., Brisson, J. G., and Wang, E. N., 2012, "Scaling of the Performance of an Air-Cooled Heat Pipe With the Addition of Multiple Modular Condensers," IEEE Intersociety Conference on Thermal and Thermomechanical Phenomena in Electronic Systems, San Diego, CA, May 30-June 1.

[4] Reay, D., and Kew, P., 2006, Heat Pipes, Fifth Edition: Theory, Design and Applications, Elsevier, Oxford, UK.

[5] Peterson, G. P., 1994, An Introduction to Heat Pipes: Modeling, Testing, and Applications, Wiley, New York.

[6] Faghri, A., 1995, Heat Pipe Science and Technology, Taylor and Francis, New York.

[7] Chi, S. W., 1976, Heat Pipe Theory and Practice, McGraw-Hill, New York.

[8] Vasiliev, L. L., 2005, "Heat Pipes in Modern Heat Exchangers," Appl. Therm. Eng., 25(1), pp. 1-19.

[9] Maydanik, Y. F., 2005, "Loop Heat Pipes," Appl. Therm. Eng., 25(5-6), pp. 635-657.

[10] Ku, J., 1999, "Operating Characteristics of Loop Heat Pipes," 29th International Conference on Environmental Systems, Denver, CO, July 12-15.

[11] Nagano, H., and Ku, J., 2007, "Start-Up Behavior of a Miniature Loop Heat Pipe With Multiple Evaporators and Multiple Condensers," 45th Aerospace Sciences Meeting and Exhibit, Reno, NV, January 8-11.

[12] Anderson, W. G., Hartenstine, J., Ellis, M., Montgomery, J., and Peters, C., 2010, "Electronics Cooling Using High Temperature Loop Heat Pipes With Multiple Condensers," Power Systems Conference, Fort Worth, TX, November 2-4.

[13] Ku, J., Ottenstein, L., and Birur, G., 2004, "Thermal Performance of a MultiEvaporator Loop Heat Pipe With Thermal Masses and Thermal Electrical Coolers," 13th International Heat Pipe Conference, Shanghai, China, Sept. 21-25.

[14] Muto, M., Murakami, M., Nagai, H., Ueno, S., and Matsuoka, M., 2002, "Thermal Behavior of a Double-Condenser Design Lhp for Monitor of All-Sky
X-Ray Image," 32nd International Conference on Environmental Systems, San Antonio, TX, July 15-18.

[15] Kim, B.-H., and Peterson, G. P., 2005, "Experimental Study of a Reversible Loop Heat Pipe," J. Thermophys. Heat Transfer, 19(4), pp. 519-526.

[16] Muraoka, I., Ramos, F. M., and Vlassov, V. V., 2001, "Analysis of the Operational Characteristics and Limits of a Loop Heat Pipe With Porous Element in the Condenser," Int. J. Heat Mass Transfer, 44(12), pp. $2287-2297$.

[17] Kariya, H. A., Koveal, C., Allison, J. M., Kelley, M., Mccarthy, M., Brisson, J. G., and Wang, E. N., 2009, "A Capillary-Pumped Loop Heat Pipe With Multi-Layer Microstructured Wicks," International Workshop on Micro and Nanotechnology for Power Generation and Energy Conversion Applications, Washington DC, December 1-4.

[18] Rosenfeld, J. H., and Gernert, N. J., 2008, "Life Test Results for Water Heat Pipes Operating at $200^{\circ} \mathrm{C}$ to $300^{\circ} \mathrm{C}$," Space Technology and Applications International Forum, Albuquerque, NM, February 10-14.

[19] Pittinato, G. F., 1978, "Hydrogen Gas Generation in Water Heat Pipes," J. Eng. Mater. Technol., 100(3), pp. 313-318.

[20] Petrick, S. W., 1972, "Hydrogen Gas Generation in Water/Stainless Steel Heat Pipes," Winter Annual Meeting of the American Society of Mechanical Engineers, New York, November 26-30.

[21] Anderson, W. G., Dussinger, P. M., Bonner, R. W., and B., S. D., 2006, "High Temperature Titanium/Water and Monel/Water Heat Pipes," 4th International Energy Conversion Engineering Conference and Exhibit San Diego, CA, June 26-29.

[22] Kariya, H. A., 2012, "Development of an Air-Cooled, Loop-Type Heat Pipe With Multiple Condensers," Ph.D. thesis, Massachusetts Institute of Technology, Cambridge, MA.

[23] Hanks, D. F., 2012, "Design, Fabrication, and Characterization of a MuiltiCondenser Loop Heat Pipe," MSc. thesis, Massachusetts Institute of Technology, Cambridge, MA

[24] Defense Advanced Research Projects Agency, 2008, "Broad Agency Announcement: Microtechnologies for Air-Cooled Exchangers (MACE)."

[25] Domínguez Espinosa, F. A., 2011, "Effect of Fabrication Parameters on Thermophysical Properties of Sintered Wicks," MSc. thesis, Massachusetts Institute of Technology, Cambridge, MA 